\title{
Innovation Capability: A Systematic Review and Research Agenda
}

\author{
Faisal Iddris \\ Halmstad University, School of Business, Engineering and \\ Science, Centre for Innovation, Entrepreneurship and Learning \\ Research (CIEL), Halmstad, Sweden
}

Faisal.iddris@hh.se

\begin{abstract}
Purpose: Innovation capability is a growing and significant area of academic research. However, there is little attempt to provide a cumulative overview of this phenomenon. The purpose of this systematic review is to synthesize peer reviewed articles published in the area to develop a conceptual framework and to aid future research.

Design/Methodology/Approach: The paper adopted a systematic review of literature on innovation capability. The final screening generated 51 articles from 30 journals from 2000-2015.

Findings: The examination and synthesis of the theoretical and the empirical articles show that (1) the authors applied narrow range of conceptual and theoretical foundations; (2) innovation capability is being investigated mostly at the firm level for about $90 \%$ of the articles, and marginally about $5 \%$ at network (supply) chain level; (3) the authors define innovation capability in different ways and use diverse set of dimensions to measure innovation capability; (4) there is potential for future research across firms in innovation management disciplines.
\end{abstract}

Practical implications: The review contributes to theory development in organizational capability literature in general. Managers wishing to innovate need to examine critically and integrate some of the innovation capability dimensions proposed in this paper.

Originality: The review is unique in the sense that it provides conceptualisation of innovation capability framework.

Keywords: innovation capability, collaboration, creativity, innovation, systematic review

\section{Introduction}

The main aim of the systematic literature review is to understand how firms develop their innova-

(CC BY-NC 4.0) This article is licensed to you under a Creative Commons AttributionNonCommercial 4.0 International License. When you copy and redistribute this paper in full or in part, you need to provide proper attribution to it to ensure that others can later locate this work (and to ensure that others do not accuse you of plagiarism). You may (and we encourage you to) adapt, remix, transform, and build upon the material for any non-commercial purposes. This license does not permit you to use this material for commercial purposes. tion capability for achieving competitive advantage. The recent rapid changes in technology, consumers' taste, preferences, and general market condition means that post-industrial organisations' survival and success depend on capability to be innovative. Other scholars (Calantone, Cavusgil, \& Zhao, 2002; Mone, McKinley, \& Barker, 1998) have recognised innovation capability as a crucial source of competitive advantage in an increasingly dynamic business environment. 
There has been growing interest in the study of innovation capability among SMEs and larger firms and across disciplines. But there is little attempt by scholars to provide comprehensive overview of the topic that can guide firms on what needs to develop in order to increase innovation output (Björkdahl \& Börjesson, 2012). As a step towards advancing the notion of innovation capability research, we sought to identify those theoretical and empirical studies that investigated innovation capability at the firm/network (supply chain) level. We also made a methodological contribution by analysing the methods used in studying innovation capability and bringing consistency to a field that is poorly operationalized. Studies in the field of innovation capability are growing and are expected to continue as an area of methodological development, empirical inquiry, and theorising. We specifically examined and synthesised the conceptual and theoretical perspectives in the literature, identified the main methodological approaches, identified the main innovation capability dimensions, and summarised important measures of the dimensions. Our purpose is to inspire theoretical and empirical research by taking stock of and identifying innovation capability practices that firms undertake to stimulate innovation. The review helps to recast how firms engage in innovation activities by providing a comprehensive framework with well operationalized dimensions needed to advance deeper understanding of the innovation process and their implications for management.

The following research questions guided the systematic literature review:

1. What are the theoretical foundations that underlie the empirical and theoretical studies of innovation capability?

2. How is innovation capability studied from a methodological perspective, and in what context is it studied?

3. What are the main dimensions of innovation capability investigated at the firm/network (supply chain) level?

The next section presents related work. This is followed by the research methodology. This is also followed by the findings of the review. It is then followed by discussion, conclusion and direction for future research.

\section{Related Work}

Innovation capability is influenced by external and internal factors that are mainly explanatory factors of firms' innovation process and/or the outcome of the process. We identified few literature reviews on innovation capability (see for example, Assink, 2006; Frishammar, Kurkkio, Abrahamsson, \& Lichtenthaler, 2012; Bell \& Figueiro, 2012; Slater, Mohr, \& Sengupta, 2014). These reviews have a different focus on innovation capability. For example, Assink's (2006) literature review focused on inhibitors of disruptive innovation capability. He conducted extensive review to identify inhibitors of disruptive innovation capabilities. The main inhibitors identified include inability to unlearn obsolete mental models, a successful dominant design, a riskaverse corporate climate, innovation process mismanagement, lack of adequate follow-through competencies, and the inability to develop mandatory internal and external infrastructure.

Frishammar, Kurkkio, Abrahamsson, and Lichtenthaler (2012) literature review focused on process innovation capability; specifically they examined the extent to which desired innovation process outcomes is materialised in the manufacturing sector. Their review proposed strategy, collaboration, and culture as the main dimensions of innovation capability. In contrast, Slater, Mohr, and Sengupta (2014) provided a literature review on radical product innovation capability; they developed a model of radical product innovation success. Their review identified senior leadership, organisational culture, organisational architecture, radical innovation product development process, and product launch strategy as the main innovation capability dimensions. Focusing on firms in developing countries, Bell \& Figueiro's (2012) literature review focused on 
innovation capability of firms from developing/emerging economies (latecomer firms). Their review shows that latecomer firms' innovation capability depends on their ability to engage in deliberate efforts to build up, use, and manage different learning mechanisms within their boundaries and in collaboration with buyers, suppliers, producers, users, universities, R\&D institutes, and consulting firms. All the above articles reviewed so far employed narrative or traditional approachs in their reviews. Thus, the uniqueness of this review is the use of a systematic literature review approach to generate the innovation capability dimensions, which was then used to develop the conceptual framework (See Table 3 later in the paper.). Second, the review provided operationalization of the dimensions to aid future empirical research needed for theory development in the area of organisational capabilities.

\section{Methodology}

There is now a growing interest in systematic review in management literature (Denyer \& Neely, 2004). "A systematic review is designed to help engender a sense of collective endeavour, relevance, and openness among researchers so as to prevent expensive and fruitless repetition of effort and to assist in linking future research to the questions and concerns that have been posted by past research" (Thorpe, Holt, Macpherson, \& Pittaway, 2005, p.258). A systematic review differs from traditional narrative reviews by adopting a systematic process that is scientific, transparent, and replicable (Tranfield, Denyer, \& Smart, 2003). This review follows a three-stage approach proposed by Tranfield et al. (Tranfield et al., 2003):

1. Planning the review: setting the objectives, developing the proposal and protocol;

2. Conducting the review: identifying, selecting, assessment, extracting, and synthesizing the relevant articles;

3. Reporting and dissemination of the results: reporting the descriptive analysis such as authors, contributions, countries, and the key emerging themes.

The approach for this research entailed extensive searches of Scopus and Emerald Databases covering 15 years (2000-2015). Using Halmstad University's digital library resources, the search was conducted between $4^{\text {th }}$ and $8^{\text {th }}$ February, 2015. The review process started with the reading of innovation management books and influential articles on innovation capability. This allowed for the identification of keywords which were employed in the subsequent search for the review articles. First, a keyword "innovation capability" OR "innovation capabilities" was entered into the two databases. The keyword was used to search for titles, abstract, and keywords in peer reviewed articles published articles in journals. The initial search generated 3542 articles from Scopus database and 178 from Emerald database. A search function in both databases was used to exclude articles that did capture the following keywords *innovation*,*dynamic capabilities*, *organizational learning*, *innovation performance* and *innovation capability*. After this process the search results generated a sample of 120 articles. The results of the 120 articles were grouped into A, B, and C list (Thorpe et al., 2005). "A" was defined as studies that were definitely relevant. "B" was defined as studies whose relevance was not clear at first. "C" was defined as studies that were less relevant or where the nature of the research work was unclear (Thorpe et al., 2005, p. 258).The relevance is in relation to the scope of the study, i.e., innovation capability building. If an article, for example, investigates innovation capability using number of patents or product launch as the main dimensions, without explicit reference to innovation capability building activities such as knowledge generation and continuous learning, then the article is excluded from the review. Other articles that were excluded were those that focused on technological innovation capabilities as that fell outside the scope of this review.

There were 70 articles that were relevant, 22 partially relevant and 8 less relevant. The relevant assessment of the articles in this review was subjected to the author's understanding and the pur- 
Innovation Capability

pose of the research. In the second stage, the full-text of the combined A (22) and B (70), making up (92) articles, was read in detail in order to ensure substantive relevance. Here the articles that were excluded were those that were narrowly focused, for example, those that used investment in $\mathrm{R} \& \mathrm{D}$, number of patents citations, and number of product launches as the only measure of innovation capability. Through this process, 41 articles were rejected from the analysis. As a result 51 articles were found to address firms' innovation capability building process. The next section presents the findings of the review.

\section{Findings}

This section presents the descriptive analysis as follows:

- Analysis by Journal (Figure 1)

- The comprehensive overview of the selected articles is presented in chronological order (Table 1).

- Analysis by date of publication (Figure 2)

- Analysis by Country (Figure 3)

- Analysis by level/unit

- Analysis by theoretical approach

- Analysis by methodology used

- European Journal of Innovation Management 6

- Journal of Engineering and Technology Management 4

- The Journal of Product Innovation Management 3

- Int. J. Knowledge Management Studies 2

- Industrial Marketing Management 2

- Technovation $\underline{R} \& d$ Management 2

- Canadian Journal of Development Studies/Revue 1 canadienne d'études du développement

- Journal of Economic Geography 1

- Scandinavian Journal of Forest Research 1

- Action Learning: Research and Practice 1

- Creativity and Innovation Management 1

- International Journal of Business Innovation and Research 1

- International Journal of Business Innovation and Research 1

- Technological Forecasting \& Social Change 1

- Engineering Management, IEEE Transactions on 1

- Int. J. Entrepreneurship and Innovation Management 1

- Journal of Management Development 1

- Organization science 1

- International Journal of Innovation Management 1

- International Journal of manpower 1 
- Industrial Management \& Data Systems 1

- The Journal of Product Innovation Management 1

- Int. J. Technology Management 1

- Int. J. Intelligent Enterprise 1

- Journal of Organizational Change Management 1

- Research Policy 1

- Journal of Knowledge Management 1

- International Journal of Production Research 1

- Int. J. Business Innovation and Research 1

- International Journal of Productivity and Performance Management 1

- Baltic Journal of Management 1

- Management Research Review 1

- Knowledge and Process Management 1

- Supply Chain Management: An International Journal 1

- Research-technology management 1

- International Journal of Production Economics 1

- International Marketing Review 1

Figure 1. Number of articles that focused specifically in innovation capability

The analysis by journal aims to show the journals that serve as outlets for publications dealing with innovation capability and innovation management in general in this review. There were a total of 32 journals made up of the selected articles. Figure 1 shows the list of journals and the number of articles in this review. The top 3 journals: European Journal of Innovation Management (6), Journal of Engineering and Technology Management (4) and The Journal of Product Innovation Management (3) accounted for $25 \%$ of the publications.

Table 1 presents a comprehensive overview of the selected articles in chronological order with the titles, unit of analysis, methodology used, dimensions of innovation capability, and the theory used.

With analysis by reference to a specific theoretical approach, the review shows that 9 per cent referred to resource based view of the firm (RBV), 31 per cent to organizational capability, 10 per cent to dynamic capability, 6 per cent to intellectual capital, 2 per cent to systems theory, 2 per cent to organizational learning, and 2 per cent to concept-knowledge respectively. However, 16 per cent of the articles did not make reference to a specific theory, which does not contribute to theory development.

Analysis by methodology shows that 41 per cent used survey as the methodological approach, 8 percent literature review, 12 per cent conceptual analysis, and 39 per cent case study (see Table 1 for details). We found that in the 41 percent that used surveys, almost all were cross-sectional studies, none of them was longitudinal in nature, and only few effectively combined survey and archival data or used multi-level designs. The review also indicates that there is a lesser number of the qualitative studies (39\%). 


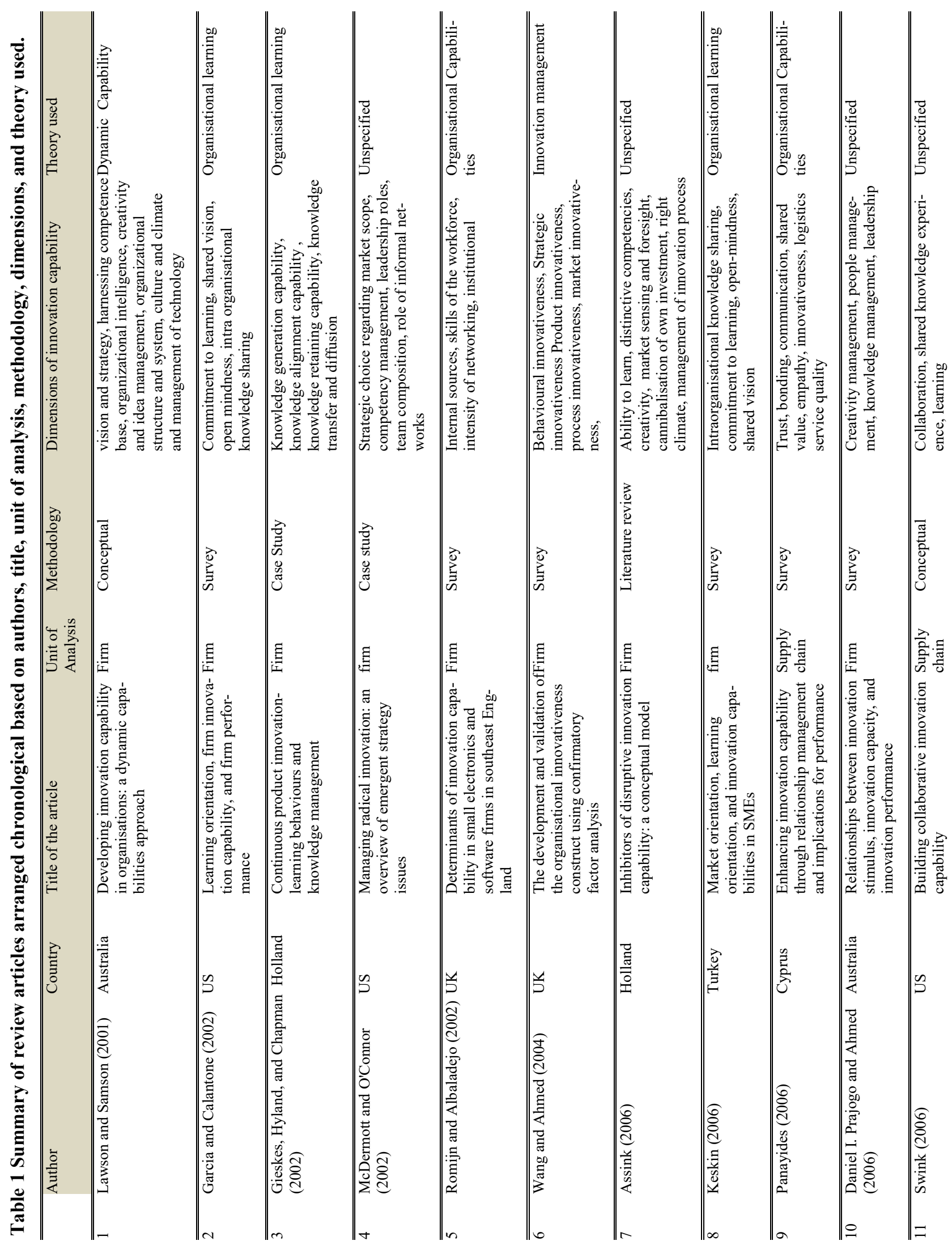




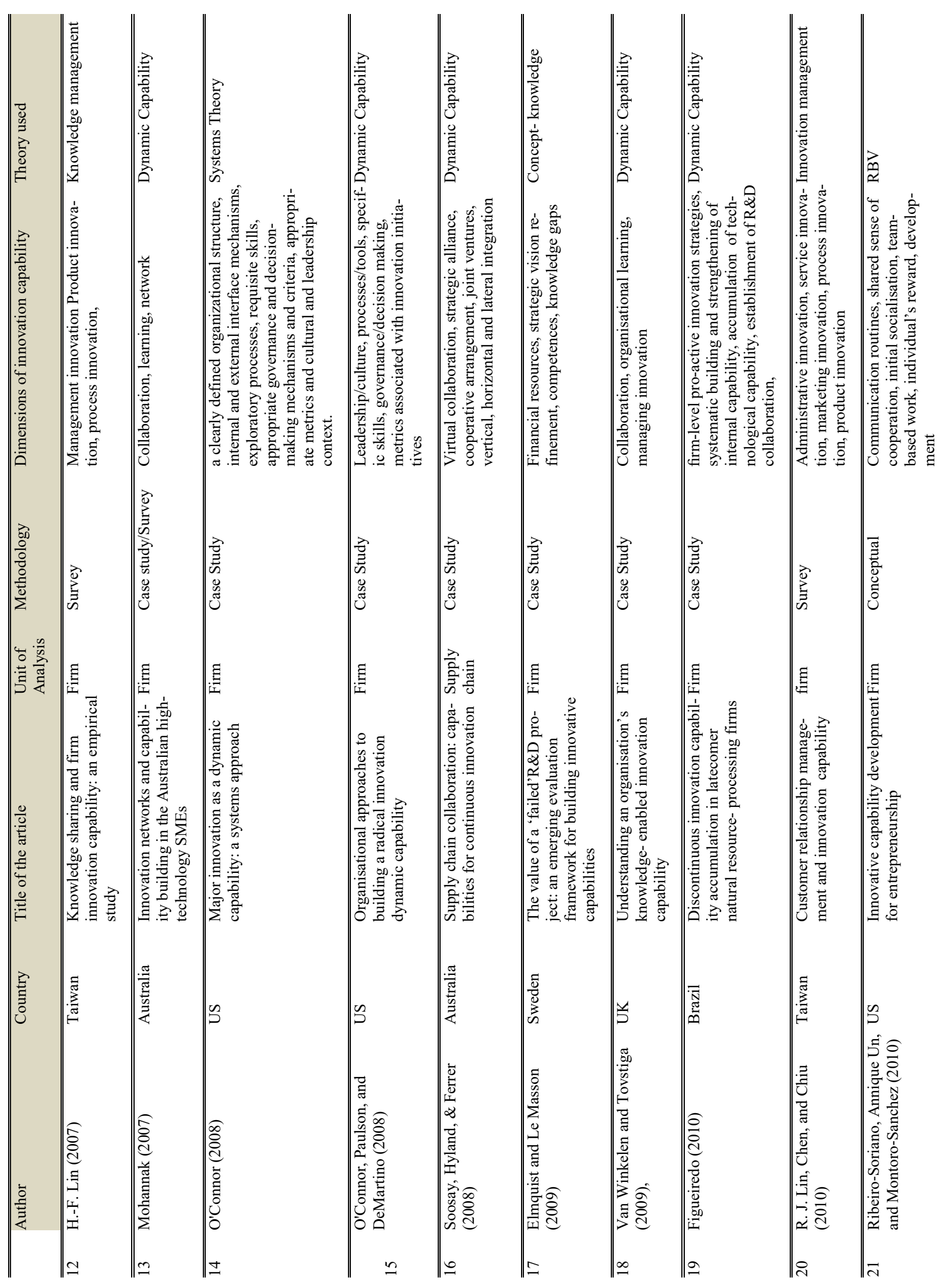




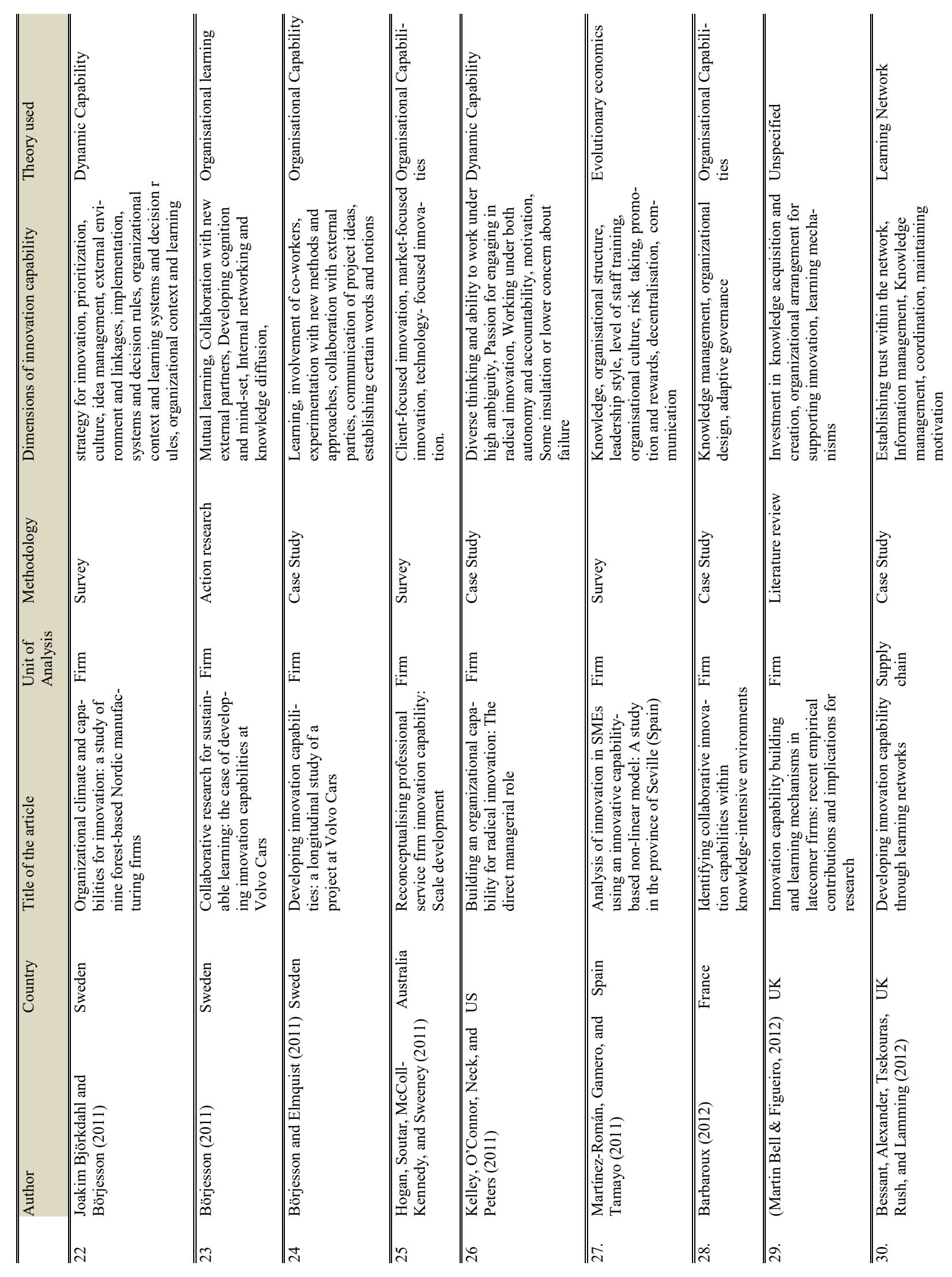




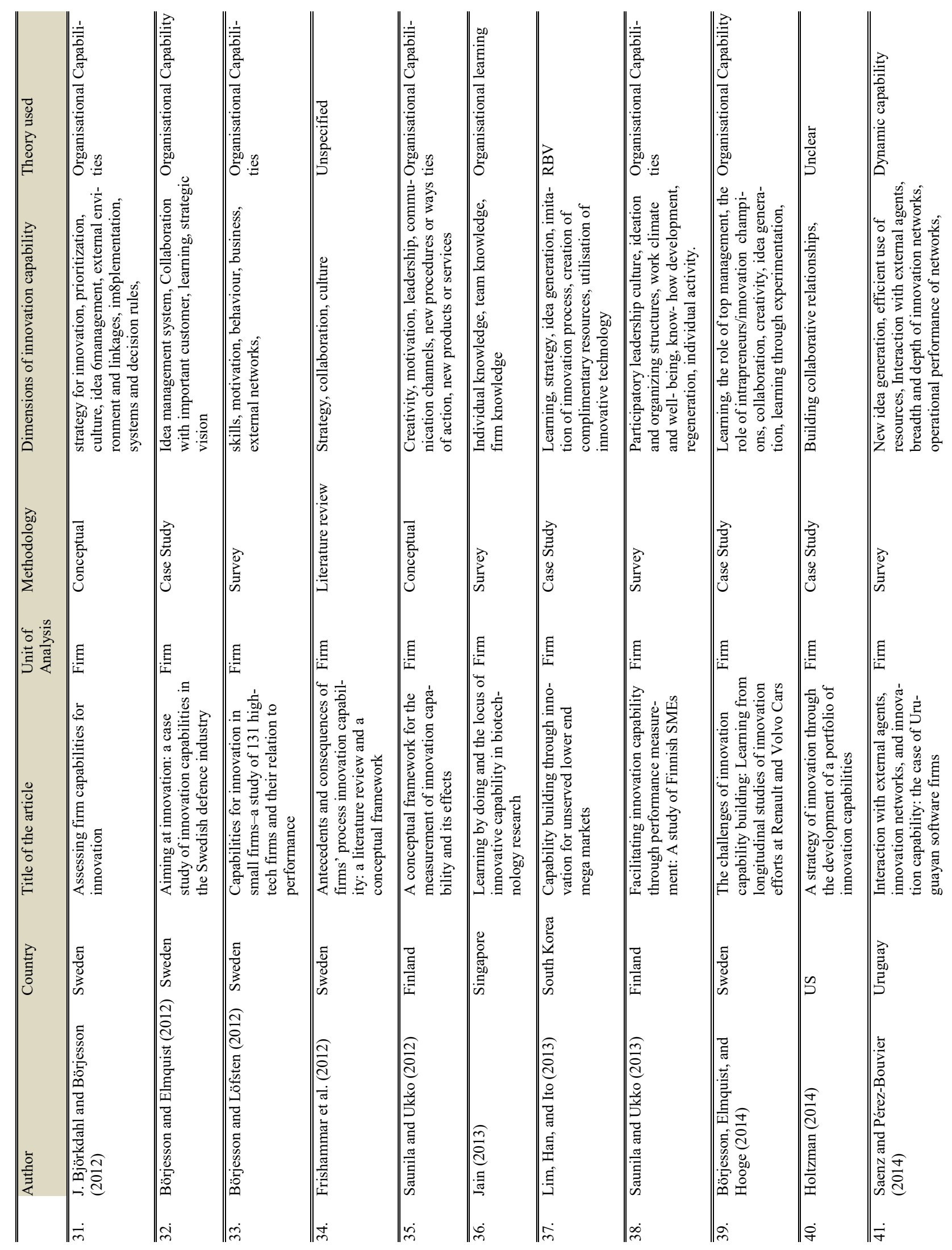




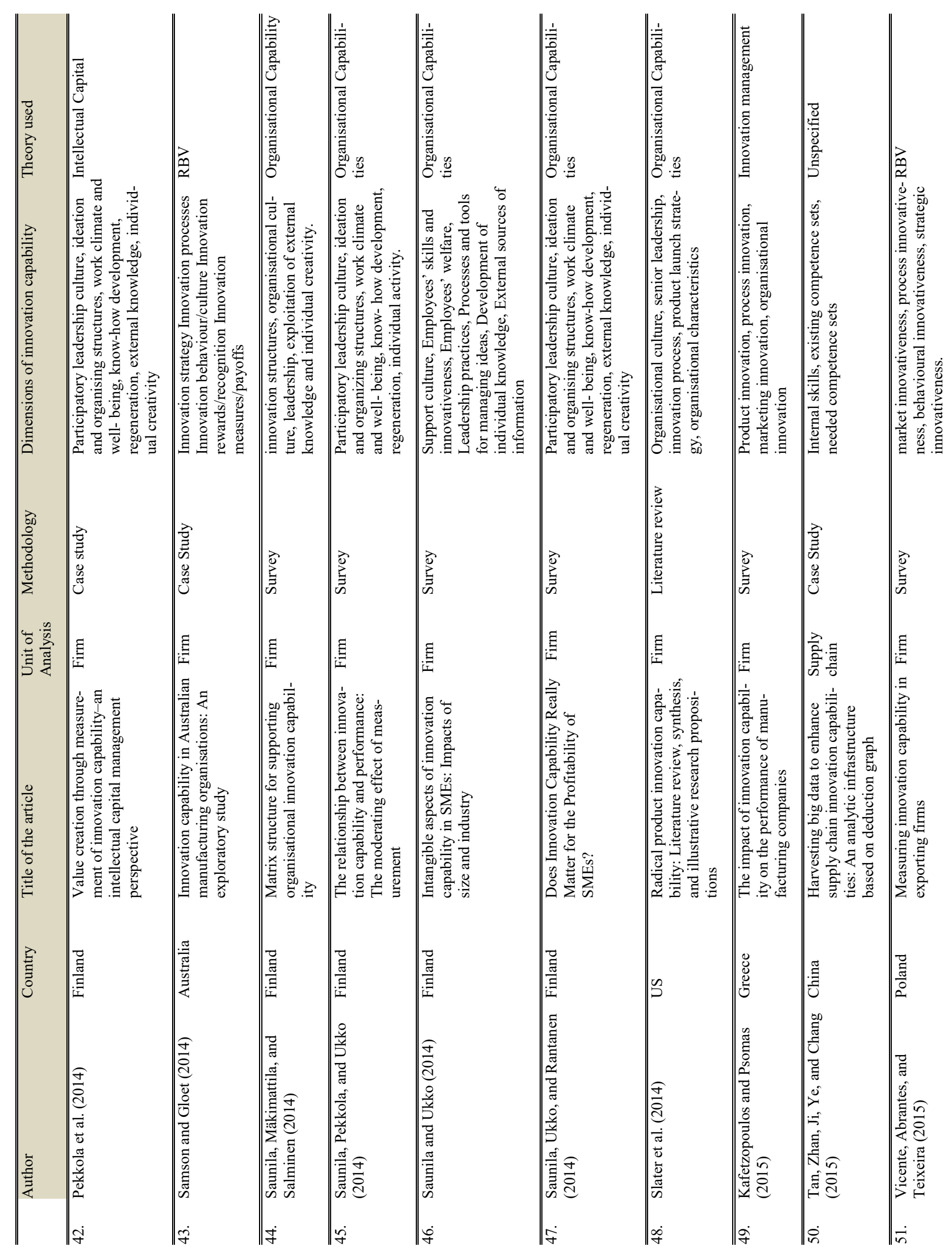


Analysis by date of publication shows that the number of studies on innovation capabilities in the field of business management and economics with innovation capability in the topic has been growing since 2000. In the bar chart presented in Figure 2 there appear to be few publications in the early 2000s with the exception of 2002 and 2006. Figure 2 also highlights an upward trend in 2012 and 2014 when 8 and 10 articles respectively were published. The three articles published in the first five months of 2015 signal growing interest in innovation capability as a field of study.

The unit of analysis for each of the study indicates that 5 articles $(9.8 \%)$ focused on supply chain while 46 articles $(90.20 \%)$ focused on firm level. This shows a high research interest in innovation capability by researchers focusing on a firm as a unit of analysis, and little research on innovation capability in the context of supply chain or network level. Specifically, $14 \%$ focused on service sector, $37 \%$ on manufacturing, $29 \%$ on combined manufacturing/service sector, and $18 \%$ on SMEs.

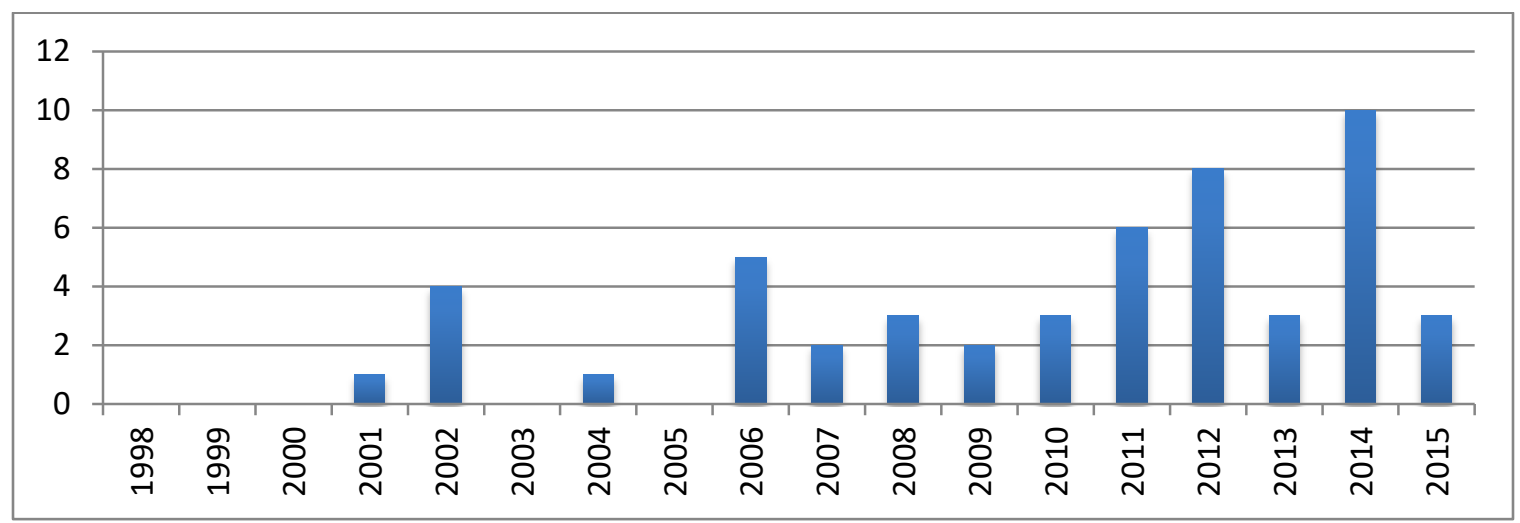

Figure 2. Analysis by date of article publication

Analysis by country shows different interests and experiences. Table 1 reports on the countries where the study was conducted. Figure 3 shows that US and Sweden have 9 articles each, Finland 7 articles, and Australia 6 articles, with no studies from countries in Africa and the Middle East. The next sections present definition of innovation capability and overview of innovation capability dimensions.

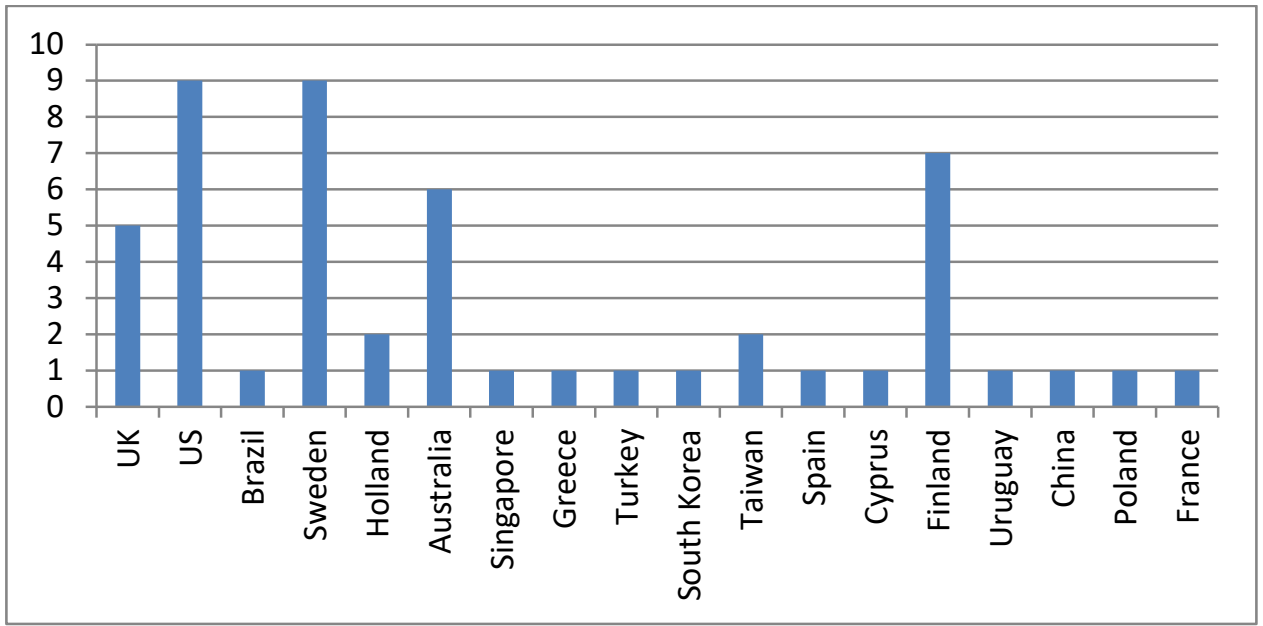

Figure 3. Analysis by country 


\section{Definition of Innovation Capability}

The first content analysis in the systematic review focuses on how innovation capability is defined. The articles reviewed indicate lack of consensus on how innovation capability is defined. Generally, the authors described innovation capability either explicitly or implicitly. Only five papers explicitly defined innovation capability (Assink, 2006; Hogan et al., 2011; Lawson \& Samson, 2001; Saunila \& Ukko, 2013; Wang \& Ahmed, 2004). Generally, the authors made reference to the following terms: 'knowledge transformation', 'learning', 'idea generation', and 'processes'. Thus, in this review innovation capability refers to a firm's ability to generate innovation through continuous learning, knowledge transformation, creativity, and exploitation of internal and external resources available to the firm.

\section{Overview of Innovation Capability Dimensions}

The following section presents a consolidation of key thematic areas (innovation capability dimensions) identified in this review. The dimensions were identified after extensive reading of each of the selected 51 articles. In most of the articles, the innovation capability dimensions are explicitly stated, for example, vision and strategy, harnessing competence base, organizational intelligence, creativity and idea management, organizational structure and system, culture and climate, and management of technology were mentioned by Lawson and Samson . Strategy for innovation, prioritization, culture, idea management, external environment and linkages, implementation, systems and decision rules, organizational context and learning systems and decision rules, organizational context and learning were mentioned by Joakim Björkdahl and Börjesson (2011). As a result, 233 innovation capability dimensions were identified (see, Table 1, column 7 for details). The dimensions were imported into Nvivo software to calculate the weighted percentage. After that, the "frequency function" of the Nvivo software was initially used to generate the 100 most recurring themes. The search, using the Nvivo frequency function continued until the eight dimensions with the highest weighted percentages emerging from the 233 dimension. The final result, as displayed in Table 2 shows the most important dimensions in this review. The rational for the calculation of the weighted percentage is to identify the most recurring themes or concepts and also to consolidate the number of innovation capability dimensions into a conceptual framework in order to aid future empirical research.

Table 2. Weighted percentage

\begin{tabular}{lc}
\hline Innovation Capability Dimensions & Weighted \\
\hline Knowledge management & 7.69 \\
Organisational learning & 5.13 \\
Organisational Culture & 5.13 \\
Leadership & 4.40 \\
Collaboration & 3.66 \\
Creativity & 2.93 \\
Idea management & 2.56 \\
Innovation strategy & 2.56 \\
\hline
\end{tabular}

It should be noted that the ranking in Table 2 only shows the frequency of the innovation capability dimensions as identified in the 51 selected articles. Subsequently, a literature search was undertaken by using references in the selected papers to do cross-referencing. Through that process the items required for the operationalisation of the main innovation capability dimensions were identified. To ensure that the innovation capability dimensions have similar meanings as identified in this review, we specifically look for the sub-dimensions that correctly measure them. For example, Amabile's (1997) concept of creativity with sub-dimensions, such as reward and recognition for creative ideas, allowing mistakes when experimenting with new ideas, availability of 
resources, granting employee freedom to engage in innovative activities, has been used to measure creativity dimension of innovation capability in several prior studies. The measuring items and their source can be found in (column 2 of Table 3). The main innovation capability dimensions are elaborated next.

Table 3. Operationalisation of Innovation Capability Dimensions Identified

\begin{tabular}{|c|c|}
\hline $\begin{array}{l}\text { Dimensions of Innova- } \\
\text { tion capability }\end{array}$ & Sub-dimensions \\
\hline $\begin{array}{l}\text { Knowledge manage- } \\
\text { ment }\end{array}$ & $\begin{array}{l}\text { Gold and Arvind Malhotra (2001) } \\
\text { - } \quad \text { use of IT to create, share, store, and use knowledge } \\
\text { - } \quad \text { generating new knowledge from existing knowledge } \\
\text { - } \quad \text { acquiring knowledge about suppliers. } \\
\text { - } \quad \text { use feedback from projects to improve subsequent projects } \\
\text { - } \quad \text { processes for knowledge distribution in the firm } \\
\text { - } \quad \text { exchanging knowledge with business partners. } \\
\text { - } \quad \text { knowledge security processes }\end{array}$ \\
\hline Organizational culture & $\begin{array}{l}\text { E. Martins and F. Terblanche (2003); Lawson and Samson (2001) } \\
\text { - } \quad \text { empowered employees } \\
\text { - } \quad \text { availability of creative time } \\
\text { - } \quad \text { good channel of communication. } \\
\text { - } \quad \text { support for change in the organisation } \\
\text { - } \quad \text { autonomy for employees and middle level management } \\
\text { - } \quad \text { freedom for risk taking and experimentation } \\
\text { tolerance for employee mistakes }\end{array}$ \\
\hline Organisational learning & $\begin{array}{l}\text { Aggeri et al. (2009); March (1991) } \\
\text { - } \quad \text { organisation-wide training and development activities } \\
\text { - } \quad \text { organisational search } \\
\text { - } \quad \text { experimentation } \\
\text { - } \quad \text { customer involvement through user experience } \\
\text { - } \quad \text { accumulation of lesson and experiences } \\
\text { - } \quad \text { partnership (alliances, inter-firm relationships, networks) } \\
\text { - } \quad \text { participatory decision making } \\
\text { opportunity for risk taking }\end{array}$ \\
\hline Leadership & $\begin{array}{l}\text { Aragón-Correa, García-Morales, and Cordón-Pozo (2007); Lawson } \\
\text { and Samson (2001) } \\
\text { - } \quad \text { motivating the rest of the company instead of controlling } \\
\text { - } \quad \text { coordination of lower, middle and top level activities } \\
\text { - } \quad \text { encouraging employees to try new ideas without fear of } \\
\text { failure or its consequences } \\
\text { - encouraging employees participation in innovation activi- } \\
\text { ties } \\
\text { - establishing structures for supporting innovation activities }\end{array}$ \\
\hline
\end{tabular}


- $\quad$ shared process and knowledge across departments

- share information with customers

- share information with suppliers

- $\quad$ support acquisition of knowledge externally

- joint planning across departments

- cooperation with universities and research centres in innovation activities

- cooperation with consultant for innovation activities

\begin{tabular}{|c|c|}
\hline Creativity & $\begin{array}{l}\text { Amabile (1997); Amabile, Conti, Coon, Lazenby, and Herron } \\
\text { (1996) } \\
\text { - } \quad \text { reward and recognition for creative ideas } \\
\text { - } \quad \text { value individual contributions } \\
\text { - } \quad \text { Setting of achievable objectives } \\
\text { - } \quad \text { Availability of resources including materials, funds, facili- } \\
\text { ties and information } \\
\text { - } \text { Allowing staff to work on challenging task } \\
\text { - } \text { Mistakes are allowed when experimenting with new ideas } \\
\text { - Free time for creative exercise } \\
\text { - Flexible working schedule }\end{array}$ \\
\hline Idea Management & 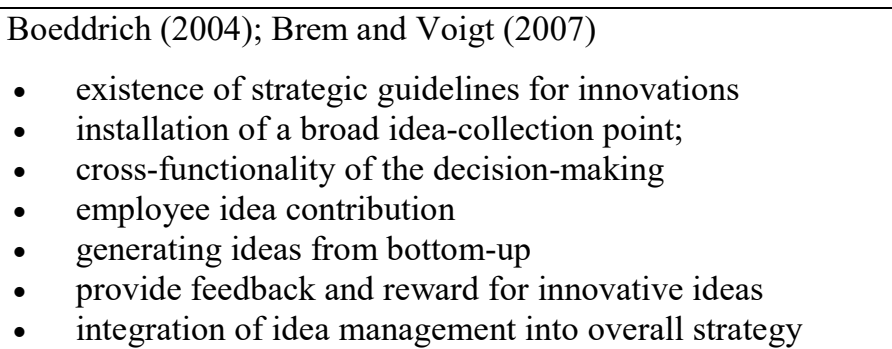 \\
\hline Innovation strategy & 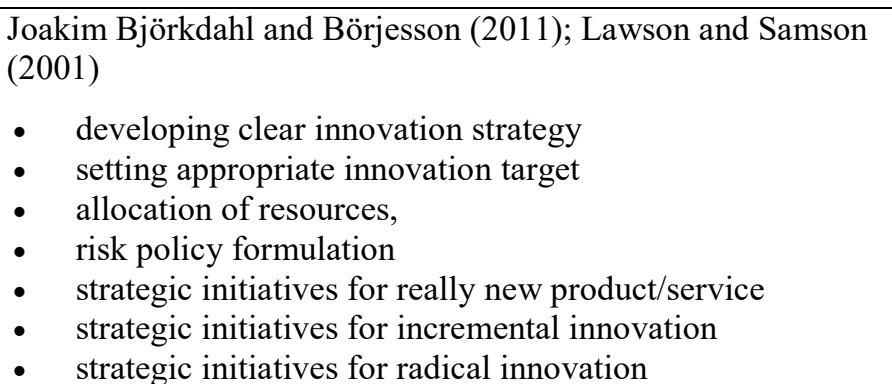 \\
\hline
\end{tabular}

\section{Discussion}

\section{Knowledge Management}

Studies by Kogut and Zander (1992) represent research underlying the importance of knowledge in innovation capability. Kogut and Zander argued that a firm's ability to exploit its knowledge and the unexplored potential of the technology promotes chances of growth, survival, and innovations. Building innovation capability involves acquiring knowledge, skills, and other elements of capability from external sources and those that are internal to the firm (Bell \& Figueiro, 2012). Börjesson (2011) investigated sustainable learning for developing innovation capabilities at Vol- 
vo Cars. She found that developing capabilities is related to change, but developing capabilities requires insider knowledge that is crucial for understanding of innovation capability building process. A study by Bessant et al. (2012) shows that the value chain of some firms became part of co-operating systems and shared knowledge systems. That helped development of standardized measuring systems and improved recovery rates. This helped improve the supply chain efficiency between sawmill and furniture manufacturers.

Research by Yusr, Othman, Mokhtar, and Don (2014) suggests that manufacturing companies' ability to manage knowledge management process significantly, enhanced their innovation capability. Their analysis shows that knowledge management positively influenced the manufacturing firms' innovation capability. Likewise, a study by Tamer Cavusgil, Calantone, and Zhao (2003) focused on the role of tacit knowledge in manufacturing and service firms innovation capability building effort. The results revealed that tacit knowledge transfer positively influenced the firms' innovation capability. Research by Soosay et al. (2008) shows that the logistics manager shared knowledge with customers and suppliers, to the extent that some of the firms were even able to access suppliers database, which led to an enhancement of innovation capability among logistics firms investigated. Statistical analysis by H.-F. Lin (2007) suggests that innovation involves a wide range of knowledge sharing process that facilitates the implementation of processes, ideas, and products. They also found that workers ability to share knowledge significantly influences the firms innovation capability. Gold and Arvind Malhotra (2001) examined knowledge management focusing on organizational capabilities. Their result indicates that the firm's culture, structure, and technology together with effective techniques of knowledge acquisition, conversion, application, and protection are important for organizational performance. Knowledge management systems of firms generate, store, and share knowledge and information that can support organizational innovation activities.

\section{Organisational Culture}

Lawson and Samson (2001), Çakar and Ertürk (2010), and E. C. Martins and F. Terblanche (2003) have all recognized organizational culture as a driving force for innovation capability. An organization that promotes empowerment of employees, tolerance, effective communication between focal firms and significant partners, and positive attitude towards achieving organizational goals can be seen to promote an innovation culture. Innovation culture can be described as a firm's attitude towards exploring and implementing ideas that facilitate the firm's innovative thinking and activities (Björkdahl \& Börjesson, 2012). Research by Björkdahl and Börjesson (2011) demonstrated that innovation culture was positive in all the firms investigated. This is because the culture of the firms permitted individuals who were less than successful in an attempt to be creative to be given a second opportunity. This attitude encourages employees to be innovative. A study by Samson and Gloet (2014) reveals that each of the manufacturing companies investigated had in place sn innovation-oriented culture that shaped behaviours and allocated the resources necessary to achieve systematic innovation and positive business outcomes. A study by Çakar and Ertürk (2010) examined organisational culture and empowerment of innovation capability of SMEs. The results from their research indicate that organizational culture positively influences innovation capability through the mediation of employee empowerment. Thus, promoting a culture of employee empowerment, open communication, support for change, and employee risk taking initiatives can significantly influence the capability to innovate.

\section{Organisational Learning}

Learning has been highlighted as one of the most important dimensions of innovation capability (Bessant et al., 2012; Calantone et al., 2002). Brown and Duguid (1991) described learning as a bridge between working and innovating. Thus, learning activities should be present in the culture 
of an organization to permit the utilization of internal and external expertise needed to promote innovation. The influence of learning on innovation capability has been widely documented in innovation management literature (Assink, 2006; Börjesson, 2011; Lawson \& Samson, 2001). For example, evidence from Börjesson (2011) shows that Volvo's Vision 2020 project 'learning-bydoing' or 'hands-on learning' involved experimentation with relatively small innovations (e.g., car subsystems). The insights developed through the learning process were shared throughout the Volvo car manufacturing company. This contributed to the development of organizational capabilities. Jain (2013) used patent data from 1979 to 2007 of 20,886 scientists working in 611 biotechnology firms in Canada and in the US to investigate learning the influence of innovative capability. The results revealed that innovative capability and innovation activities in general were influenced by learning by doing. Similarly, a research by Calantone et al. (2002) revealed that learning facilitates the implementation of processes, ideas, and products among the broad spectrum of US industries. Thus, support for accumulation of work experiences into routines, interfirm exchange of experiences and information, as well as involvement of customers and suppliers in learning activities, can contribute to innovation capability building.

\section{Leadership}

The role of leadership in supporting and stimulating innovation by creating overall conducive environment has been established in the literature (Lawson and Samson, 2001; Pekkola et al., 2014; Saunila, Pekkola, \& Ukkoet, 2014). Empirical evidence from O'Connor et al. (2008) shows that a strategic mandate from a company's leadership to a group of workers who were responsible for making radical innovation led to a positive results. A study by Prajogo and Ahmed (2006) shows that leadership stimulates innovation performance through innovation management. Their analysis indicated that managing people, creativity, and idea generation through strong company's leadership had a strong influence on innovation activities. This value shows a positive relationship between leadership and innovation. A study by Samson and Gloet (2014) demonstrates that strong leadership and role modelling drove sustained innovation capability among manufacturing firms investigated. Thus, the ability of organizational leadership to establish a structure of coordinating employees, encouraging employee work participation, generating ideas without fear, and motivating the rest of the company can significantly contribute to innovation capability building.

\section{Collaboration}

The extant literature has stressed the importance of collaboration in innovation generating activities (Powell, Koput, \& Smith-Doerr, 1996; Swink, 2006). Van Winkelen and Tovstiga (2009) identified external collaboration and internal collaboration as some of the key factors that contribute to firms' innovation capability building. Collaboration helps firms to share information and knowledge among interacting parties. The value of collaboration regarding capability is shown in the empirical work of Börjesson (2011), and her conclusion is supported by Sáenz, Revilla, and Knoppen (2014). In studying Volvo Cars manufacturing company's innovation capability, Börjesson (2011) notes that in order for Volvo car to achieve its vision 2020, Volvo car collaborated with new external partners, including universities, to gain knowledge in the field of consumer behaviour and energy utilisation, a particular knowledge discipline that Volvo Cars' lacked internally. The frequent collaboration with external parties contributed to a change of perspective and the building of new networks, which in turn facilitated knowledge a development needed for innovation activities in Volvo cars. Mohannak's (2007) study shows that the biotechnology firms in Australia frequently carry out R\&D through collaboration with research institutions, universities, suppliers, and customers in the process of building their innovation capability. Similarly, empirical evidence by Börjesson and Löfsten (2012) shows that small high-tech firms' collaboration with universities and research institutions led to the testing of new ideas and devel- 
opment of technical knowledge and capabilities that the small high-tech firms lacked in-house. The importance of collaboration is further demonstrated empirically by Soosay et al. (2008). The authors investigated how collaboration facilitated innovation capability in the firms' supply chain. Their result showed that logistics firms engaged in joint planning, shared process, and knowledge with their network members. The collaborative initiatives helped the focal firms to embark on both incremental and radical innovations. Thus, when firms collaborate externally, through joint planning, shared process and knowledge, and shared information, the firms can experience high increase in innovativeness.

\section{Creativity}

Creativity has been identified as an important dimension that feeds into innovation (Amabile, 1997; Loewenberger, 2013). Creativity can differ between a group, an organization, or a culture, and it can also change over time since it is context specific (Martins \& Terblanche, 2003). Thus, Ford (1995) suggests that creativity can be evaluated at the level of person, organization, industry, profession, or wider. Thus, in this review, creativity is evaluated on the basis of the ability of a focal firm to create the enabling environment to enhance innovative behaviour of employees. In general, organizations are required to enhance innovation by ensuring an environment that supports creativity and idea generation (Prajogo \& Ahmed, 2006). Saunila and Ukko (2012) identified creativity, motivation, leadership, communication channels, idea creation and assessment, and new procedures as some of the key elements of innovation capability that influence business performance. Their results indicate that individual creativity positively influences a firms' innovation capability. They further argue that individuals' innovation capability serve as a basis for a firms' overall innovation capability. Innovation revolves around human activity, hence enhancing competence of employees in relation to creativity, teamwork, learning, leadership, network capabilities; and entrepreneurship could be critical for generation of innovations successfully, (Aramburu \& Sáenz, 2011). Vicente et al.’s (2015) empirical evidence suggests that managers can support innovation capability by stimulating creativity, experimentation, and openness to new ideas within the firm. Creativity is found to be dependent on management's ability to create opportunities and an enabling environment and to provide the needed resources (Amabile, 1997; Pekkola et al., 2014; Prajogo \& Ahmed, 2006; Saunila, Mäkimattila, \& Salminen, 2014). Empirical evidence from Amabile et al. (1996) shows that creativity enhances organizational innovativeness. Therefore, organizations can facilitate innovation by creating and maintaining an environment that supports idea generation and creativity. Such enabling conditions include the provision of resources and opportunities. Organizational encouragement and provision of sound working environment can stimulate creativity and innovation.

\section{Idea Management}

A firm's ability to convert ideas into new and improved products, services, or ways of doing things (Björkdahl \& Börjesson, 2012) has been recognized as a major contributor to innovation capability building. Idea management process enables a focal firm's interaction with customers, suppliers, employees, and other business partners to generate and implement innovative products or service ideas. The results of a study by Brem and Voigt (2007) show that integrated idea management helped the firms to gather a large number of ideas and contributions from suppliers, customers, and competitors in their innovation activities. Similarly, empirical findings from Bessant et al. (2012) show that the UK supply chains in oil and gas, semiconductor, IT equipment, chemicals, and aerospace sectors all seek to engage participants as active innovators by way of contributing ideas and experiences along their value chain. Likewise, empirical findings from Tan et al., (2015) suggest that SPEC, a leading eyeglasses manufacturer based in China, used idea management systems to collect and analyse different kinds of data, including existing customers' preferences and characteristics such as videos and photos of available eyeglasses products. The idea 
management systems enabled SPEC's different units and departments to synchronise their activities in a new product development and to optimize the manufacturing process along its value chain, hence, engaging customers, suppliers, and other stakeholders in idea generation as well as generating ideas from bottom up within a company has the tendency to facilitate innovation capability.

\section{Innovation Strategy}

Innovation strategy determines the degree to which a firm mobilises available resources to achieve organizational goals in the face of uncertain marketing environments. An innovation strategy facilitates organisation's ability to identify external opportunities and match those opportunities with internal capabilities so as to explore new markets and deliver innovative products (Wang \& Ahmed, 2004). Aramburu and Sáenz's (2011) studies revealed that innovation strategy and network had significant influence on innovation capability. Similarly, the emphasis on innovation strategy in innovation capability was discussed by Vicente et al. (2015). The authors argue that managers can develop innovativeness by stimulating creativity, formulating, implementing and monitoring appropriate innovation strategy. Börjesson and Elmquist (2012) investigated innovation capability building in the Swedish defence industry in order to respond to disruptive, non-technical changes to its environment. Their evidence shows that the Swedish defence industry innovation capability effort requires clear strategic changes of developing innovation capability. A study by Wang and Ahmed (2004) provides empirical evidence regarding the role of strategic innovativeness in innovation capability. Their regression analysis indicates that strategic innovativeness had the second highest coefficient value of 0.79 . This means that strategic innovativeness have potential influence on current and future innovative capability of organizations. Samson and Gloet (2014) found that formulation of risk policy, setting of priorities, and resource allocation contributed to innovation capabilities of the manufacturing firms investigated. Strategy determines the alignment of the existing resources, systems, and processes that firms need to undertake in order to meet market uncertainty. A firm without innovation strategy might not be on the pathway toward innovation.

\section{Conclusion}

The objective of this review has been to systematically review and integrate evidence from innovation management literature and to develop a comprehensive conceptual framework. The review adds novel insights to research on innovation capability in three ways.

First, this research provides a comprehensive and systematic review of innovation capability building, which has been overlooked in the extant literature. Existing literature reviews rather focused on process innovation capability and radical product innovation capability (Frishammar et al., 2012; Slater et al., 2014) and innovation capability in latecomer firms (Bell \& Figueiro, 2012).

Second, the dimensions of the innovation capability were identified through a systematic process; we were able to extract 233 innovation capability dimensions after carefully reading all the 51 selected articles. The 233 innovation capability dimensions were subjected to frequency analysis to identify the most recurrent dimensions. The result shows that knowledge management, organisational culture, organisational learning, leadership, collaboration, creativity, idea management, innovation strategy, and trust were the most frequently used dimensions in the study of innovation capability from 2000-2015. This approach differs from the traditional approach where the dimensions were identified arbitrarily. We believe that this unique approach adds more value to conceptualisation of innovation capability and guiding theory development, by eliminating the implicit bias of the researcher (Tranfield et al., 2003). 
Third, the framework (Table 3) generates conceptual clarity of what the main innovation capability dimensions might be. In addition, providing comprehensive operationalisation of the innovation capability dimensions that can facilitates theoretical and empirical investigation and analysis of a firm's innovativeness, using some or part of the framework.

\section{Direction for Future Research}

In this section we discuss existing research gaps and directions for future research with respect to our research questions: (1) theoretical foundation, (2), methodology, and (3) innovation capability dimensions.

\section{Theoretical foundation - future directions}

The first question of this review aims at discovering the theoretical foundation underlying the conceptual and empirical studies on innovation capability. Our findings indicate that about 16 percent of the studies reviewed did not make reference to any specific theory in their research. Where theoretical perspectives were used, approximately 50 percent of the studies used one of these theories: resource-based view of the firm (RBV), organisational capabilities, and dynamic capabilities. Ten percent of the articles used organisational learning, and two percent used knowledge management as the theoretical foundation. Based on our review, we suggest two theoretical foundations that are useful in studying innovation capabilities: organisational learning with emphasis on exploration and exploitation and knowledge based theory of the firm. These two perspectives are a good fit into the context of a firm's or network (supply) level because they first capture non-technical aspects of innovation capability building. In addition, they place emphasis on the role of cognitive and experiential search, problem solving, knowledge formation, and routines. We acknowledge that organisational capabilities, resource based view of the firm, and dynamic capabilities are the cornerstone of innovation capabilities. However, they are widely used in the existing research. Therefore, in this case, we focus on theory suggestions that may address major research gaps and advance theory development in a fundamental way.

First, our review highlighted the importance of knowledge transformation into innovative products or services. Given the role of knowledge management in generating innovative ideas, as highlighted in the systematic literature review, we suggest knowledge-based theory of the firm (KBTF) (Nickerson and Zenger (2004) to be a useful theoretical perspective in generating knowledge or capability. Knowledge-based theory of the firm postulates that a manager's objective is to create valuable knowledge, but since this knowledge does not exist, a manager must instead choose a valuable problem. And when the problem is successfully solved through searching for alternatives, knowledge or a capability is then generated. In the review, knowledge management emerged as the most important dimension of innovation capability.

Second, literature review revealed the importance of learning to the empirical investigation of innovation capability. However there is little evidence of the explicit use of the main themes in organisational learning theory. Organisational learning with emphasis on exploration and exploitation was first introduced by March (1991). In our view, organisational learning contributes significantly to adaptive processes that fit well into innovation process. The concepts of exploration and exploitation are valuable in helping researchers to understand that refinement and extension of existence competences can occur through 'exploitation' and that experimentation through searching for alternatives can occur through 'exploration'. One key element of exploration is an iterative process that generates novelty. In all, the trade-off between exploration and exploitation improve an organisation's performance and innovativeness. Organisational learning may generate knowledge that can be stored in the organisational memory. This knowledge can be used for repetitive tasks or unique tasks in an organisation. The review shows that organisational learning and knowledge-based theory can be useful in describing and explaining innovation process. 
In all, the systematic review demonstrates the need to both broaden and deepen the theoretical foundation of research on innovation capabilities. We have restricted our suggestions here to two theoretical foundations. However, the exact theory that a researcher will use in the study of innovation capability should be carefully selected to provide support for specific propositions or research questions. Theories, if carefully selected, will provide lenses through which researchers propose and investigate new and innovative questions.

\section{Methodological perspective - future directions}

The second research question of the review sought to address the methodological approach that is used to investigate innovation capability. The systematic review shows multiple qualitative, quantitative, and few mixed-method approaches with little agreement on how to define and measure innovation capability.

\section{Sample selection}

The systematic review highlighted issues regarding selection of the samples. First, the existing body of research on innovation capability is limited in terms of the countries covered. The majority of the studies on innovation capability in this review have been conducted in Europe ( 57 percent); this is followed by the US (18 percent), Australia (12 percent), and Asia (10 percent). There are no studies from the Middle East or Africa in this review. We acknowledge bias towards over reliance on the articles from English medium journals. Our inability to access non-English medium journals may account for underrepresentation of articles from developing countries. Innovation capability is a global phenomenon, however; diversity in terms of the articles is absent from the literature. Most of the authors used combination of qualitative and/or quantitative approaches; however, less attention was paid to the selection of samples that could guide theory development about innovation capability in different geographical or national context. More studies in relation to innovation capabilities in emerging economies in countries from South America, Africa, and the Middle East are needed.

\section{Methods}

Qualitative studies provide in depth and detailed examination of the organizational context of studying innovation capabilities. For example, it will be more informative for future research to identify managerial actions that constantly stimulate capabilities for innovation. Qualitative studies of employees' capability to be innovative can be helpful in identifying all types of skills or knowledge that employees believe they possess and the process through which employees acquired those capability. The result of these qualitative studies can facilitate undertaking of more quantitative studies with emphasis on the factors driving employees' innovation capabilities and their consequences for competitive advantage. Such research can provide powerful insights into how organisations can influence an employee's knowledge and skills (innovation capabilities). It is important to highlight the fact that quantitative studies of innovation capabilities included in this review suffer from some limitations.

First, the majority of the studies measured innovation capability with the mere intention of the companies to develop those capabilities. In addition, capabilities are built overtime. Thus, failure to take that perspective into account provides insufficient data for analysis. Second, all measures were based on a questionnaire instrument completed by a single respondent at a point in time. This limitation makes it difficult for the researchers to make causal inference, and it may also provide a different result if another time-frame is chosen. Future research needs to measure both objective and subjective innovation capability dimensions to determine the extent to which selfreported and perceptual examination of innovation capabilities converge with objective assessment of measurable dimensions. Also, studies need to assess the independent variables of interest 
differently from measures of innovation capabilities. More suited research on innovation capabilities is required to capture extensive and in-depth findings about ability to be innovative in a wide range of contexts. Methodologically, this may involve extensive use of ethnographic research involving participative and observational research approach.

\section{Innovation Capability Dimensions}

The third research question of this review focused on the main innovation capability dimensions investigated in the literature. To answer this research question we thoroughly read all the selected 51 articles in order to identify the main innovation capability dimensions investigated. This enabled us to extract 233 dimensions (see Table 1, column 7 for details). These dimensions were subjected to frequency analysis in Nvivo software to determine the most frequently recurring themes. The resulted weighted percentages for each of the innovation capability dimensions (see, (Table 2) are knowledge management (7.69), organisational learning (5.13), organisational culture (5.13), leadership (4.40), collaboration (3.66), creativity (2.96), idea management (2.56), and innovation strategy (2.56). The associated values of the dimensions indicate the relative importance and how frequently the authors investigated these dimensions. The review shows that knowledge management is the most important dimension of innovation capability and the least important is innovation strategy. However, managers need to complement it with other dimensions in the process of building innovation capability. Thus, future studies are needed to empirically test the proposed theoretical model across different levels of analysis, industries, and geographical locations, to better understand innovation capability building at a firm and/or network (supply chain) level.

\section{Implications}

This review contributes to theory development in organisational capability. This is because future research can assist in theory building by empirically testing the proposed relationships. Innovation capability is a relatively new phenomenon and therefore a theory development will be an important contribution to understanding this multi-dimensional construct.

Second, it demonstrates that building innovation capability will require the integration of relevant dimensions which can be operationalized. The dimensions and sub-dimensions can facilitate both quantitative and qualitative studies, which can further enhance deeper understanding of innovation capability building effort on the part of a company.

Third, this review shows that academicians and practitioners need to pay attention to innovation capability building in the context of supply chain or network perspective, given the little research in that field. This is because innovation generation tends to emanate from the contribution of network members, since a single firm hardly possesses all the tangible and intangible resources required for generating innovation.

\section{Limitations}

Although, the present review focused on 51 articles published in 32 different journals, we cannot conclude that the 51 articles are full representations of important peer review publications. It is possible that some research articles relating to innovation capability building beyond 2015 and before the year 2000 have not been part of the database used in the review. Hence future review may extend to several databases. 


\section{References}

Aggeri, F., Elmquist, M., \& Pohl, H., (2009). Managing learning in the automotive industry; The innovation race for electric vehicles. International Journal of Automotive Technology and Management, 9(2), $123-147$.

Amabile, T. M. (1997). Motivating creativity in organizations: On doing what you love and loving what you do. California Management Review, 40(1), 39-58.

Amabile, T. M., Conti, R., Coon, H., Lazenby, J., \& Herron, M. (1996). Assessing the work environment for creativity. Academy of Management Journal, 39(5), 1154-1184.

Aragón-Correa, J. A., García-Morales, V. J., \& Cordón-Pozo, E. (2007). Leadership and organizational learning's role on innovation and performance: Lessons from Spain. Industrial Marketing Management, 36(3), 349-359.

Aramburu, N., \& Sáenz, J. (2011). Structural capital, innovation capability, and size effect: An empirical study. Journal of Management \& Organization, 17(03), 307-325.

Assink, M. (2006). Inhibitors of disruptive innovation capability: A conceptual model. European Journal of Innovation Management, 9(2), 215-233.

Barbaroux, P. (2012). Identifying collaborative innovation capabilities within knowledge-intensive environments. European Journal of Innovation Management, 15(2), 232-258. doi: $10.1108 / 14601061211220995$

Bell, M., \& Figueiro, P. N. (2012). Innovation capability building and learning mechanisms in latecomer firms: Recent empirical contributions and implications for research. Canadian Journal of Development Studies, 33(1), 14-40.

Bessant, J., Alexander, A., Tsekouras, G., Rush, H., \& Lamming, R. (2012). Developing innovation capability through learning networks. Journal of Economic Geography, 12(5), 1087-1112. doi: $10.1093 / \mathrm{jeg} / \mathrm{lbs} 026$

Björkdahl, J., \& Börjesson, S. (2011). Organizational climate and capabilities for innovation: A study of nine forest-based Nordic manufacturing firms. Scandinavian Journal of Forest Research, 26(5), 488500 .

Björkdahl, J., \& Börjesson, S. (2012). Assessing firm capabilities for innovation. International Journal of Knowledge Management Studies, 5(1-2), 171-184. doi: 10.1504/IJKMS.2012.051970

Boeddrich, H. J. (2004). Ideas in the workplace: A new approach towards organizing the fuzzy front end of the innovation process. Creativity and Innovation Management, 13(4), 274-285.

Börjesson, S. (2011). Collaborative research for sustainable learning: The case of developing innovation capabilities at Volvo Cars. Action Learning: Research and Practice, 8(3), 187-209. doi: $10.1080 / 14767333.2011 .603407$

Börjesson, S., \& Elmquist, M. (2011). Developing innovation capabilities: A longitudinal study of a project at Volvo Cars. Creativity and Innovation Management, 20(3), 171-184.

Börjesson, S., \& Elmquist, M. (2012). Aiming at innovation: A case study of innovation capabilities in the Swedish defence industry. International Journal of Business Innovation and Research, 6(2), 188-201.

Börjesson, S., Elmquist, M., \& Hooge, S. (2014). The challenges of innovation capability building: Learning from longitudinal studies of innovation efforts at Renault and Volvo Cars. Journal of Engineering and Technology Management, 31(January-March), 120-140. doi: 10.1016/j.jengtecman.2013.11.005

Börjesson, S., \& Löfsten, H. (2012). Capabilities for innovation in small firms-A study of 131 high-tech firms and their relation to performance. International Journal of Business Innovation and Research, 6(2), 149-176. 
Brem, A., \& Voigt, K.-I. (2007). Innovation management in emerging technology ventures-The concept of an integrated idea management. International Journal of Technology, Policy and Management, 7(3), 304-321.

Çakar, N. D., \& Ertürk, A. (2010). Comparing innovation capability of small and medium-sized enterprises: Examining the effects of organizational culture and empowerment. Journal of Small Business Management, 48(3), 325-359.

Calantone, R. J., Cavusgil, S. T., \& Zhao, Y. (2002). Learning orientation, firm innovation capability, and firm performance. Industrial Marketing Management, 31(6), 515-524. doi: 10.1016/S00198501(01)00203-6

Denyer, D., \& Neely, A. (2004). Introduction to special issue: Innovation and productivity performance in the UK. International Journal of Management Reviews, 5(3-4), 131-135.

Elmquist, M., \& Le Masson, P. (2009). The value of a 'failed'R\&D project: An emerging evaluation framework for building innovative capabilities. R\&D Management, 39(2), 136-152.

Figueiredo, P. N. (2010). Discontinuous innovation capability accumulation in latecomer natural resourceprocessing firms. Technological Forecasting and Social Change, 77(7), 1090-1108. doi: 10.1016/j.techfore.2010.02.004

Ford, C. M. (1995). Creativity is a mystery: Clues from the investigators' notebooks. In C. M. Ford \& D. A. Gioia (Eds), Creative action in organizations: Ivory tower visions \& real world voices. Sage.

Frishammar, J., Kurkkio, M., Abrahamsson, L., \& Lichtenthaler, U. (2012). Antecedents and consequences of firms' process innovation capability: A literature review and a conceptual framework. Engineering Management, IEEE Transactions on, 59(4), 519-529.

Garcia, R., \& Calantone, R. (2002). A critical look at technological innovation typology and innovativeness terminology: A literature review. Journal of Product Innovation Management, 19(2), 110-132.

Gieskes, J. F. B., Hyland, P. W., \& Chapman, R. (2002). Continuous product innovation - Learning behaviours and knowledge management. International Journal of Entrepreneurship and Innovation Management, 2(6), 485-500.

Gold, A. H., \& Arvind Malhotra, A. H. S. (2001). Knowledge management: An organizational capabilities perspective. Journal of Management Information Systems, 18(1), 185-214.

Hogan, S. J., Soutar, G. N., McColl-Kennedy, J. R., \& Sweeney, J. C. (2011). Reconceptualizing professional service firm innovation capability: Scale development. Industrial Marketing Management, 40(8), 1264-1273.

Holtzman, Y. (2014). A strategy of innovation through the development of a portfolio of innovation capabilities. Journal of Management Development, 33(1), 24-31. doi: 10.1108/jmd-11-2013-0138

Jain, A. (2013). Learning by doing and the locus of innovative capability in biotechnology research. Organization Science, 24(6), 1683-1700.

Kafetzopoulos, D., \& Psomas, E. (2015). The impact of innovation capability on the performance of manufacturing companies the Greek case. Journal of Manufacturing Technology Management, 26(1), 104130.

Kelley, D. J., O’Connor, G. C., Neck, H., \& Peters, L. (2011). Building an organizational capability for radical innovation: The direct managerial role. Journal of Engineering and Technology Management, 28(4), 249-267.

Keskin, H. (2006). Market orientation, learning orientation, and innovation capabilities in SMEs: An extended model. European Journal of Innovation Management, 9(4), 396-417.

Kogut, B., \& Zander, U. (1992). Knowledge of the firm, combinative capabilities, and the replication of technology. Organization Science, 3(3), 383-397. 
Lawson, B., \& Samson, D. (2001). Developing innovation capability in organisations: A dynamic capabilities approach. International Journal of Innovation Management, 5(03), 377-400.

Lim, C., Han, S., \& Ito, H. (2013). Capability building through innovation for unserved lower end mega markets. Technovation, 33(12), 391-404. doi: 10.1016/j.technovation.2013.06.010

Lin, H.-F. (2007). Knowledge sharing and firm innovation capability: An empirical study. International Journal of Manpower, 28(3/4), 315-332.

Lin, R. J., Chen, R. H., \& Chiu, K. K. S. (2010). Customer relationship management and innovation capability: An empirical study. Industrial Management \& Data Systems, 110(1-2), 111-133. doi: 10.1108/02635571011008434

Loewenberger, P. (2013). The role of HRD in stimulating, supporting, and sustaining creativity and innovation. Human Resource Development Review, 12(4), 422-455.

March, J. G. (1991). Exploration and exploitation in organizational learning. Organization Science, 2(1), 71-87.

Martínez-Román, J. A., Gamero, J., \& Tamayo, J. A. (2011). Analysis of innovation in SMEs using an innovative capability-based non-linear model: A study in the province of Seville (Spain). Technovation, 31(9), 459-475. doi: 10.1016/j.technovation.2011.05.005

Martins, E. C., \& Terblanche, F. (2003). Building organisational culture that stimulates creativity and innovation. European Journal of Innovation Management, 6(1), 64-74. doi: 10.1108/14601060310456337

McDermott, C. M., \& O'Connor, G. C. (2002). Managing radical innovation: An overview of emergent strategy issues. Journal of Product Innovation Management, 19(6), 424-438.

Mohannak, K. (2007). Innovation networks and capability building in the Australian high-technology SMEs. European Journal of Innovation Management, 10(2), 236-251. doi: 10.1108/14601060710745279

Mone, M. A., McKinley, W., \& Barker, V. L. (1998). Organizational decline and innovation: A contingency framework. Academy of Management Review, 23(1), 115-132.

Nickerson, J. A., \& Zenger, T. R. (2004). A knowledge-based theory of the firm-The problem-solving perspective. Organization Science, 15(6), 617-632.

O'Connor, G. C. (2008). Major innovation as a dynamic capability: A systems approach. Journal of Product Innovation Management, 25(4), 313-330.

O’Connor, G. C., Paulson, A. S., \& DeMartino, R. (2008). Organisational approaches to building a radical innovation dynamic capability. International Journal of Technology Management, 44(1), 179-204.

Panayides, P. (2006). Enhancing innovation capability through relationship management and implications for performance. European Journal of Innovation Management, 9(4), 466-483.

Pekkola, S., Saunila, M., Sillanpää, V., Ukko, J., Parjanen, S., Salminen, J., . . Rantala, T. (2014). Value creation through measurement of innovation capability-An intellectual capital management perspective. International Journal of Intelligent Enterprise, 2(2-3), 196-212.

Powell, W. W., Koput, K. W., \& Smith-Doerr, L. (1996). Interorganizational collaboration and the locus of innovation: Networks of learning in biotechnology. Administrative Science Quarterly, 116-145.

Prajogo, D. I., \& Ahmed, P. K. (2006). Relationships between innovation stimulus, innovation capacity, and innovation performance. $R \& D$ Management 36, 5.

Ribeiro-Soriano, D., Annique Un, C., \& Montoro-Sanchez, A. (2010). Innovative capability development for entrepreneurship. Journal of Organizational Change Management, 23(4), 413-434. doi: $10.1108 / 09534811011055403$

Romijn, H., \& Albaladejo, M. (2002). Determinants of innovation capability in small electronics and software firms in southeast England. Research Policy, 31(7), 1053-1067. 
Saenz, J., \& Pérez-Bouvier, A. (2014). Interaction with external agents, innovation networks, and innovation capability: The case of Uruguayan software firms. Journal of Knowledge Management, 18(2), 447-468.

Sáenz, M. J., Revilla, E., \& Knoppen, D. (2014). Absorptive capacity in buyer-supplier relationships: Empirical evidence of its mediating role. Journal of Supply Chain Management, 50(2), 18-40.

Samson, D., \& Gloet, M. (2014). Innovation capability in Australian manufacturing organisations: An exploratory study. International Journal of Production Research, 52(21), 6448-6466.

Saunila, M., Mäkimattila, M., \& Salminen, J. (2014). Matrix structure for supporting organisational innovation capability. International Journal of Business Innovation and Research, 8(1), 20-35.

Saunila, M., Pekkola, S., \& Ukko, J. (2014). The relationship between innovation capability and performance: The moderating effect of measurement. International Journal of Productivity and Performance Management, 63(2), 234-249. doi: doi:10.1108/IJPPM-04-2013-0065

Saunila, M., \& Ukko, J. (2012). A conceptual framework for the measurement of innovation capability and its effects. Baltic Journal of Management, 7(4), 355-375. doi: 10.1108/17465261211272139

Saunila, M., \& Ukko, J. (2013). Facilitating innovation capability through performance measurement: A study of Finnish SMEs. Management Research Review, 36(10), 991-1010. doi: 10.1108/mrr-11-20110252

Saunila, M., \& Ukko, J. (2014). Intangible aspects of innovation capability in SMEs: Impacts of size and industry. Journal of Engineering and Technology Management, 33, 32-46. doi: 10.1016/j.jengtecman.2014.02.002

Saunila, M., Ukko, J., \& Rantanen, H. (2014). Does innovation capability really matter for the profitability of SMEs? Knowledge and Process Management, 21(2), 134-142. doi: 10.1002/kpm.1442

Slater, S. F., Mohr, J. J., \& Sengupta, S. (2014). Radical product innovation capability: Literature review, synthesis, and illustrative research propositions. Journal of Product Innovation Management, 31(3), 552-566.

Soosay, C. A., Hyland, P. W., \& Ferrer, M. (2008). Supply chain collaboration: Capabilities for continuous innovation. Supply Chain Management: An International Journal, 13(2), 160-169. doi: $10.1108 / 13598540810860994$

Swink, M. (2006). Building collaborative innovation capability. Research-technology Management, 49(2), 37-47.

Tamer Cavusgil, S., Calantone, R. J., \& Zhao, Y. (2003). Tacit knowledge transfer and firm innovation capability. Journal of Business \& Industrial Marketing, 18(1), 6-21.

Tan, K. H., Zhan, Y. Z., Ji, G. J., Ye, F., \& Chang, C. (2015). Harvesting big data to enhance supply chain innovation capabilities: An analytic infrastructure based on deduction graph. International Journal of Production Economics, 165, 223-233. doi: 10.1016/j.ijpe.2014.12.034

Thorpe, R., Holt, R., Macpherson, A., \& Pittaway, L. (2005). Using knowledge within small and mediumsized firms: A systematic review of the evidence. International Journal of Management Reviews, 7(4), 257-281.

Tranfield, D., Denyer, D., \& Smart, P. (2003). Towards a methodology for developing evidence-informed management knowledge by means of systematic review. British Journal of Management, 14(3), 207222.

Van Winkelen, C., \& Tovstiga, G. (2009). Understanding an organisation's knowledge-enabled innovation capability. International Journal of Knowledge Management Studies, 3(1-2), 97-115.

Vega-Jurado, J., Gutiérrez-Gracia, A., \& Fernández-de-Lucio, I. (2009). Does external knowledge sourcing matter for innovation? Evidence from the Spanish manufacturing industry. Industrial and Corporate Change, 18(4), 637-670. 
Innovation Capability

Vicente, M., Abrantes, J. L., \& Teixeira, M. S. (2015). Measuring innovation capability in exporting firms: The INNOVSCALE. International Marketing Review, 32(1), 29-51.

Wang, C. L., \& Ahmed, P. K. (2004). The development and validation of the organisational innovativeness construct using confirmatory factor analysis. European Journal of Innovation Management, 7(4), 303313.

Yusr, M. M., Othman, A. R., Mokhtar, S. S. M., \& Don, M. S. (2014). How innovation capability can be a mediate between knowledge management and innovation performance? International Business Management, 8(2), 118-125.

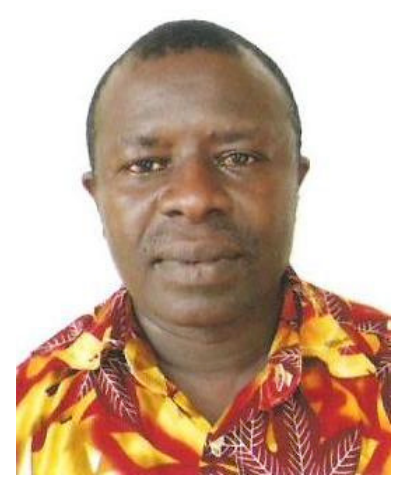

\section{Biography}

Faisal Iddris is a PhD student at Halmstad University, School of Business, Engineering and researcher in the Centre for Innovation, Entrepreneurship and Learning Research (CIEL), Halmstad University Sweden.

His research interests include innovation in supply chain, SMEs and larger organisations 